\section{Conclusions}

The building of rigs for oil-concrete or steel-is no different from similar construction work for any other purpose and it brings the expected and familiar hazards to life and limb. What is different is the requirement for deep water and the consequent siting of building yards in remotely doctored areas miles away from hospital services. The medical requirements of offshore riggers are similar to those who are drilling on land, but their doctors are separated from them by 100 miles of sea. Further, the National Health Service Act requires the provision of health care for all persons on Scottish soil, but there is no statutory requirement for the oil fields outwith this limit. It is distance, not morbidity, that makes a special case for the oil men and their medical cover. However, for the divers working under such unnatural conditions an exceptional degree of specialist support is required. In general the working party considers that the practitioners alongside the shore plants have managed to contain the new and extra demands made on them. It is anxious that offshore personnel must be given every reasonable safeguard. There are areas where further progress could and should be made to this end.

We accept that an adequate medical service for the oil related industry-especially for the continental shelf-provides a challenge to the medical profession, and it is a responsibility which must be shared between the profession, the industry, and the government.

\section{Recommendations}

(A) There should be co-ordination of the procedures and legislation relating to the medical aspects of offshore rigs.

(B) Planning authorities should broadcast any plans at the earliest moment to area health boards. In turn the boards should pass on at once intelligence on any development proposals to the G.P.s in the locality.

(C) An occupational health service should be established.

(D) Postgraduate occupational health courses should be attended by doctors attached to the oil industry.

(E) An Institute of Offshore Environmental Medicine should be built up rapidly.

(F) Medical practitioners should have ready access to top management.

(G) Managements should be informed that they do not have the right to see medical records (except with the patient's permission).

(H) A helipad should be constructed alongside Aberdeen Royal Infirmary and at Lerwick.

(I) Accommodation should be made available in Aberdeen for offshore personnel who find themselves without a roof after seeing the company doctor or on discharge from hospital.

(J) An assessment should be made as to how many N.H.S. staff have left in favour of employment by the oil industry.

\title{
Register of Newly Diagnosed Diabetic Children
}

\author{
ARNOLD BLOOM, T. M. HAYES, D. R. GAMBLE
}

British Medical fournal, 19خे5, 3, 580-583

\begin{abstract}
Summary
In November 1972 the British Diabetic Association sponsored a register to which notification was invited of all new cases of diabetes occurring in children aged 0-15 years in Great Britain and Ireland. More than 2000 cases were notified in the first two years. Notification suggested that there was a minimum yearly incidence of 7.67 cases per 100000 , though incidences varied from year to year and by geographical area. Several reports of simultaneous onset of diabetes in sibs of different ages provided evidence of clustering. A seasonal variation in incidence was found in children aged 5-15 years with peaks in the autumn and winter. The age distribution was bimodal with a main peak at about 11 years and a secondary peak at about 5 years. The sex ratio showed a male excess from 0-4 years and from 11-15 years and a female excess from 5-10 years. Overall there were slightly more male cases. Altogether $11 \%$ of patients had a first-degree relative with diabetes. The register and several investigations based on it will continue.
\end{abstract}

Whittington Hospital, London N19 3UA

ARNOLD BLOOM, M.D., F.R.C.P., Consultant Physician

Department of Medicine, Welsh National School of Medicine, Cardiff CF4 4XN

T. M. HAYES, M.B., M.R.C.P., Consultant Physician and Senior Lecturer in Medicine

Public Health Laboratory, West Park Hospital, Epsom, Surre

D. R. GAMBLE, M.B., F.R.C.PATH., Directo

\section{Introduction}

Diabetes in children still presents many unsolved problems. Though it is generally assumed that the disease is hereditary most patients have no family history of diabetes. Even when both parents are diabetic only about one in five of their offspring are likely to develop the disorder. ${ }^{12}$ In identical twins, one of whom is diabetic, the second twin remains unaffected in about half the cases. ${ }^{3}$ These findings suggest that, though heredity plays a part in the aetiology of diabetes, environmental factors must be of major importance. Little is known of the incidence of diabetes in children or of variations in its age, sex, seasonal, and geographical distribution, and epidemiological studies are of fundamental importance in the elucidation of the role of environmental factors.

The treatment of diabetes in children is equally problematic. The life expectation of such children is only about two-thirds that of normal children and the later years may be clouded by incapacity from ischaemic heart disease, by renal failure, or by blindness. Any improvement in the outlook for these patients may depend on a fuller understanding of the factors leading to diabetes and its complications.

With this background in mind the British Diabetic Association (B.D.A.) sponsored a register of newly-diagnosed childhood diabetics for use as a basis for epidemiological, virological, and other studies, and a paediatric research committee composed of diabetologists, paediatricians, epidemiologists, and virologists was convened to formulate plans for the project. The register began in November 1972 and several investigations were initiated, including an epidemiological study using data obtained by questionnaire. We report here a preliminary analysis of some of the information included in notifications and questionnaires during the first two years of the project. 


\section{Methods}

The register was based on the assumption that most children who develop diabetes are referred to hospital for initial treatment. Using the Medical Directory for 1972 , physicians and paediatricians in relevant hospitals in Great Britain and Eire were circulated with explanatory letters aimed at them, their junior staff, and the ward sisters. Notification of new cases of diabetes in children under the age of 16 years was invited and a fee of $£ 1$ offered for completion of a standard notification form. In accordance with the Medical Research Council's recommendation ${ }^{4}$ the chairman of the committee (A.B.) undertook responsibility for the confidentiality of the register, and it was agreed that communications about any child notified to the register would always be directed to the doctor in charge of the patient. It was made clear that co-operation in further studies based on the register may be sought but that notification of cases did not imply willingness to co-operate in this way.

Each notification included the patient's name, sex, date of birth, hospital number, date of diagnosis, and the name of the doctor in charge of the patient. This information was coded for computer analysis at Cardiff. On receipt of notifications questionnaires were dispatched requesting additional information, including the duration of symptoms at the date of diagnosis, to establish the date of onset, and certain background information such as family history, school attendance, and parental occupation. Completed questionnaires were received for about $70 \%$ of notified patients and though a full analysis will be published elsewhere some information obtained by questionnaire is included in the present report.

Fig. 1 shows the areas into which the country was divided in order to permit comparison between north and south and east and west.

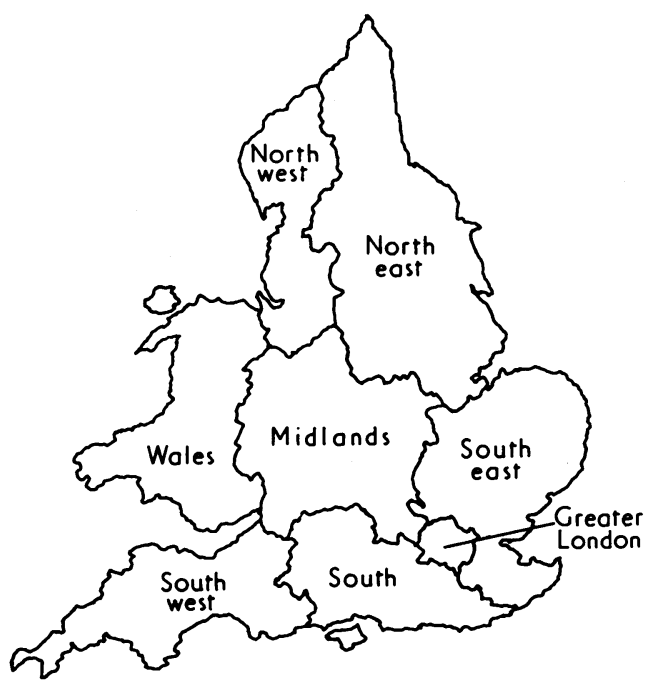

FIG. 1-Geographical areas used in analysis. Scotland and Ireland (Northern Ireland and Eire) are two further areas.

\section{Results}

\section{INCIDENCE}

Notifications in the first two years of the survey indicated an overall yearly incidence of diabetes of 7.67 per 100000 children aged 0-15 years, but the incidence varied in different areas (see table). Fewer cases were reported in Greater London and Ireland than elsewhere, and in some areas, such as the southern areas, notifications suggested a higher than average incidence. The extent to which variations in ascertainment rates were responsible for these differences was uncertain, though we thought that cases were undernotified in some London hospitals. A comparison of notifications in 1973 and 1974, however, showed that there was a decrease in 1974 in several areas, most strikingly in the south, where notifications fell from 160 to $91(\mathrm{P}<$ 0.001 ). There was no reason to believe that doctors in this area had notified fewer of their cases in 1974 than in 1973, and it seemed more likely that the area had experienced an increased incidence in 1973. This evidence of geographical variation in incidence suggested the influence of environmental factors. Reports of diabetes occurring
Notifications of Diabetes in Children aged 0-15Years by Area in 1973 and 1974. Numbers in Italics indicate Incidence Rates which Differed Significantly from Average

\begin{tabular}{|c|c|c|c|c|}
\hline \multirow[t]{2}{*}{ Area } & \multirow{2}{*}{$\begin{array}{l}\text { Population* } \\
\text { (aged } \\
0-15 \text { years) }\end{array}$} & \multicolumn{3}{|c|}{$\begin{array}{c}\text { Diabetes Notifications per } 100000 \text { Children } \\
\text { per Year } \\
\text { (No. of Notified Cases) }\end{array}$} \\
\hline & & 1973 & 1974 & Both Years \\
\hline $\begin{array}{l}\text { North east } \\
\text { North west } \\
\text { Midlands } \\
\text { Greater London } \\
\text { South east } \\
\text { South } \\
\text { South west } \\
\text { Wales } \\
\text { Scotland } \\
\text { Ireland }\end{array}$ & $\begin{array}{l}2577000 \\
1836600 \\
2214800 \\
1662300 \\
1497900 \\
1236000 \\
535900 \\
681800 \\
1438000 \\
1140700 \dagger\end{array}$ & $\begin{array}{c}8.03(207) \\
8.17(150) \\
8.04(178) \\
5.23(87) \\
10.42(156) \\
12.94(160) \\
10.08(54) \\
7.19(49) \\
8.62(124) \\
4.47(51)\end{array}$ & $\begin{array}{c}6.93(178) \\
6.00(110) \\
8.04(178) \\
5.90(98) \\
10.82(162) \\
7.36(91) \\
8.21(44) \\
7.33(50) \\
6.19(89) \\
5.17(58)\end{array}$ & $\begin{array}{c}7.47(385) \\
7.08(260) \\
8.04(356) \\
5.56(185) \\
10.61(318) \\
10 \cdot 15(251) \\
9.14(98) \\
7.26(99) \\
7.41(213) \\
4.78(109)\end{array}$ \\
\hline All areas & 14821000 & $8 \cdot 20(1216)$ & $7 \cdot 14(1058)$ & $7.67(2274)$ \\
\hline
\end{tabular}

${ }^{*}$ Mid 1971 populations from 1971 Census. ${ }^{10}$

†Census data not available. An estimated figure has been inserted (Total population $\times 0.2532$ ).

almost simultaneously in sibs of different ages provided further evidence of environmental factors. Two sibs developed diabetes within a week in two cases and within a month in a third family; in a fourth case three sibs developed diabetes within three months.

\section{SEASONAL VARIATION}

There was a definite seasonal variation in the number of new cases each month among older children, but children aged less than 5 years showed less variation and no obvious seasonal pattern (fig. 2). Children aged 5-15 years had a high winter incidence from December to March, an autumn peak about September or October, and a nadir in June and July. Symptoms were usually present for several weeks before diagnosis, and the seasonal pattern by date of onset of symptoms $^{5}$ anticipated that shown here by up to a month and therefore differed slightly. The seasonal pattern was consistent in its main features in both years and was similar to that seen in smaller numbers in earlier surveys. ${ }^{6-8}$

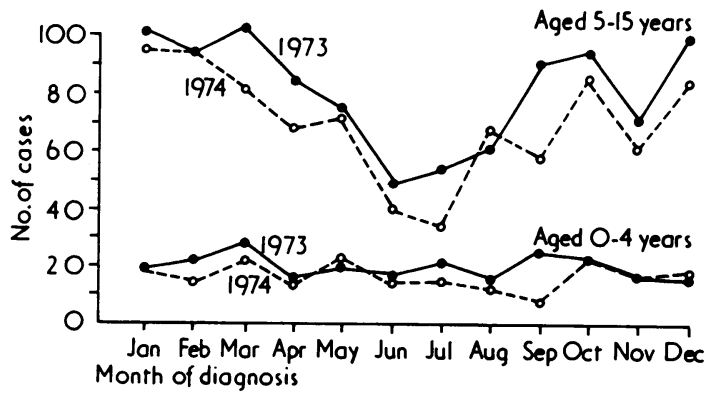

FIG. 2-Number of cases notified according to month of onset and age group in 1973 and 1974.

\section{AGE INCIDENCE}

The age distribution at onset (fig. 3) showed that the incidence increased with age to a peak at about 11 years with a smaller peak at about 5 years. After the age of 11 or 12 the incidence fell sharply, and more rapidly in girls than in boys. This decline may have been partly due to teenage children being referred to adult clinics, but there was no evidence that notification was less likely by doctors in adult clinics than by paediatricians. In any case a peak incidence at about 11 has been described by others, ${ }^{9-11}$ and a peak incidence from 10 to 15 years has been found in diabetic clinics which accept both children and adults. ${ }^{7} 9$

The sex ratios showed that there were more boys notified among the 0-4-year-olds, more girls among the 5-10-year-olds, and more boys among the 11-15-year-olds. Overall more boys (1279) than girls (1145) were notified, but there may have been a greater deficit of teenage boys notified for the reason given above. 


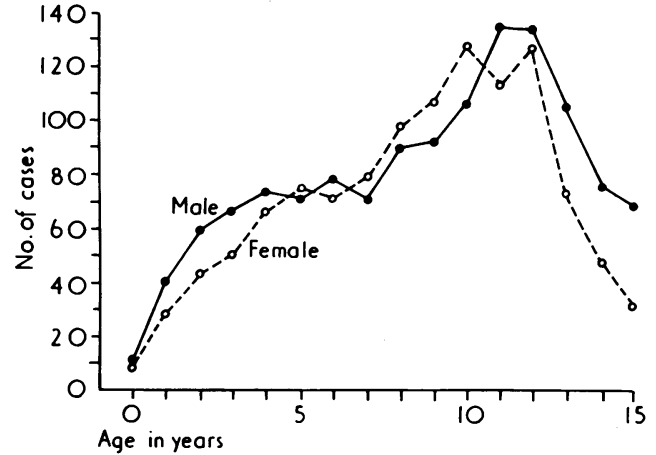

FIG. 3-Age distribution of cases notified according to sex.

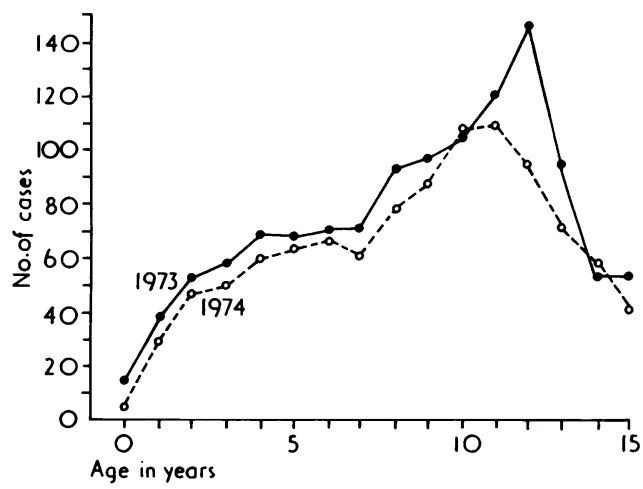

FIG. 4-Age distribution of cases notified according to year of onset.

The age incidence patterns were similar in both years (fig. 4). There were fewer cases in 1974 and the greatest decrease occurred in patients aged 11-13 years, possibly because of the smaller autumn peak in that year. The peak incidence in 1973 occurred at 10 and 11 years, but in 1974 there was a sharp peak at 12 years; there may, therefore, be considerable year-to-year variation in the age incidence pattern.

\section{FAMILY HISTORY OF DIABETES}

The first 1400 questionnaires returned indicated a history of diabetes in a first-degree relative in $154(11 \%)$ of the patients. Though the numbers were too small for firm conclusions there was no evidence that the age and seasonal incidence patterns in patients with a family history differed from those in patients without such a history.

\section{Discussion}

The accuracy of incidence rates is dependent on a known and stable level of ascertainment. We have, therefore, begun an investigation to determine our ascertainment rate by reference to the case notes of all children admitted to hospital with diabetes in six area health authorities during a defined period. With this information we may be able to relate data obtained from the register to true incidence rates.

The notifications received indicated an average yearly incidence rate of at least 7.67 per 100000 but variations in incidence between areas and years were probably greater than could be accounted for by variations in the level of ascertainment. This irregular incidence suggests the influence of environmental factors, and reports of the simultaneous onset of diabetes in sibs of different ages lend further support to this suggestion. Four such cases were reported to us in the two years and a fifth case not notified to the B.D.A. has been reported in the U.K. during the same period. ${ }^{12}$ Simultaneous diabetes in sibs might be expected to occur occasionally by chance but it is surprising that there should have been five cases in two years, particularly when in one family three sibs were affected.
The seasonal variation in incidence is a further indication of environmental influence. Though there was a higher incidence in the colder winter months the incidence was otherwise poorly correlated with temperature changes ${ }^{8}$ and factors that might be dependent on temperature such as caloric intake or physical activity. Infections are probably the factors most likely to be responsible because of their seasonal prevalence; indeed there is a remarkable similarity between the seasonal pattern of juvenile diabetes and the seasonal pattern of infections of childhood. ${ }^{13}$ Most of these infections are minor respiratory illnesses, and it seems unlikely that they would cause diabetes though they might constitute a stress factor sufficient to precipitate overt diabetes in patients who had previously sustained islet cell damage. Alternatively, diabetes may result from virus infections that specifically damage the islet cells, in which case the seasonal pattern of diabetes could reflect that of aetiological virus infections. Thus, viruses with peak prevalence in the autumn or winter might be involved, or, if a lag period intervened between infection and onset of diabetes, the responsible viruses might be prevalent some months before the respective seasonal peaks of diabetes. It is unlikely, however, that a latent period would be longer than several months without the seasonal pattern becoming blurred or lost. These suggestions are not mutually exclusive but on our present knowledge it is not possible to say which, if either, occurs.

The age incidence of childhood diabetes seems to be bimodal with peaks at about 5 and 11 years of age, which may indicate that there are two groups with different aetiologies. It has been suggested that these peaks are associated with pubertal changes or with spurts in the growth rate, ${ }^{9}$. but neither of these suggestions seems likely to provide a complete explanation. The most rapid growth occurs in the first few years of life, when the incidence of diabetes is minimal. Both sexes have a peak in diabetes at about the age of 5 years but only boys have a spurt in growth rate at this age. ${ }^{14}$ From 6 to 10 years the incidence of diabetes increases but growth decreases. The second diabetes peak occurs at about 11 years but the maximum growth rate occurs at 14 in boys and 12 in girls. Menarche does not occur until about 13 years in the British Isles. ${ }^{15}{ }^{16} \mathrm{~A}$ further argument against an association with pubertal changes is that the ages at which they occur vary little from year to year, whereas the age of peak incidence of diabetes may vary by a year or more from one year to another. ${ }^{5}$ The different sex ratios we found clearly show that sex is involved in some way, but it seems unlikely that puberty is a major determinant; it is of interest that sex may affect the incidence of virus infection ${ }^{17}$ and its manifestations. ${ }^{18}$

Major environmental changes in childhood are associated with school attendance and it has been suggested that the peaks in incidence of juvenile diabetes may be associated with starting school at 5 and transferring from primary to secondary school at 11 years. If this is so children who start school at a younger age than usual may develop diabetes earlier than those who start at the statutory age, and there is some evidence that this may be true. ${ }^{5}$

Oakley et al." found that $13 \%$ of diabetic children had a history of diabetes in a first-degree relative, which is similar to our own estimate of $11^{\circ} \mathrm{o}$. The figure for non-diabetic children is about $2 \%,{ }^{11}$ which supports the idea of a genetic factor in patients with a family history. If diabetes in patients with no family history has a different aetiology epidemiological differences might have been expected in the two groups, but though numbers were too small for firm conclusions no such differences were found.

The results obtained to date from investigations based on this register justify its continuation for at least five years. This will provide further data on secular and geographical variations in incidence and allow fuller use of the register for other investigations of genetic, biochemical, immunological, and virological aspects of juvenile diabetes.

We thank the British Diabetic Association and all those who helped to launch the register, particularly the many physicians who have 
notified cases and completed so many questionnaires. Our thanks are also due to Mr. P. Samuel, lecturer in computer science, at the Welsh National School of Medicine, Cardiff.

\section{References}

1 West, K. M., Diabetes, 1960, 9, 379

2 Cooke, A. M., et al., British Medical fournal, 1966, 2, 674.

3 Tattersall, R. B., and Pyke, D. A., Lancet, 1972, 2, 1120.

${ }^{4}$ Medical Research Council, British Medical fournal, 1973, 1, 313.

${ }^{5}$ Gamble, D. R., Proceedings of a Workshop-Conference on the Genetics of Diabetes, Gottingen 1975. Berlin, Springer-Verlag, in press.

${ }^{6}$ Adams, S. F., Archives of Internal Medicine, 1926, 37, 861.

${ }^{7}$ Gamble, D. R., and Taylor, K. W., British Medical fournal, 1969, 3, 631.

${ }^{8}$ Gamble, D. R., Postgraduate Medical Fournal, 1974, 50, Suppl. 3, p. 538.

9 White, P., Diabetes in Childhood and Adolescence, p. 61. Philadelphia, Lea and Febiger, 1932.
10 Danowski, T. S., Diabetes Mellitus, with Emphasis on Children and Young Adults, p. 129. Baltimore, Williams and Wilkins, 1957.

11 Oakley, W. G., Pyke, D. A., and Taylor, K. W., Clinical Diabetes and its Biochemical Basis, p. 591. Oxford, Blackwell, 1968.

12 Cudworth, A. G., and Woodrow, J. C., Lancet, 1974, 2, 1153.

${ }^{13}$ Dingle, J. H., Badger, G. F., and Jordan, W. S., Illnoss in the Home, A Study of 2500 Illnesses in a Group of Cleveland Families, Cleveland, Ohio, Press of Western Reserve University, 1964.

14 Stewart, H. C., and Stevenson, S. S., Textbook of Pediatrics, ed. W. E. Nelson, 7th edn., p. 50. Philadelphia, Saunders, 1959.

15 Marshall, W. A., and Tanner, J. M., Archives of Diseases of Childhood, 1969, 44, 291.

${ }_{16}$ Marshall, W. A., and Tanner, J. M., Archives of Disease in Childhood, 1970, 45, 13.

17 Spicer, C. C., Fournal of Hygiene, 1961, 59, 143.

${ }^{18}$ Lennette, E. H., Magoffin, R. L., and Khoug, E. G., fournal of the American Medical Association, 1962, 179, 687.

19 Office of Population Censuses and Surveys, Census 1971, County Report and Census 1971, Scotland, Population Tables. London, H.M.S.O., 1971.

\title{
Social Medicine
}

\section{Community Participation in Primary Health Care}

\author{
P. M. M. PRITCHARD
}

British Medical fournal, 1975, 3, 583-584

\section{Summary}

A two and a half year's experience of a community participation group has shown that this can have a valuable role in suggesting practicable improvements in a group practice. Topics discussed by the group (which is composed of one representative from every known organization in the area) have included problems of receptionists; the role of the individual ancillary worker; and teaching in general practice. The high attendance rate at the group's meetings testifies to the community's interest in primary health care services.

\section{Introduction}

The setting up of community health councils (C.H.C.s) in the reorganized National Health Service has aroused interest in securing the community's involvement in health services. Many of the problems encountered in formulating and implementing the proposals for C.H.C.s were experienced by the general practitioners and other health professionals working from the Berinsfield Health Centre when a community participation group (C.P.G.) was established in 1972.

C.H.C.s are an important innovation in the N.H.S. because for the first time they give the population being served by local health services the right and obligation to comment on all those services. The aim of the councils is to enable a continuing

The Health Centre, Berinsfield, Oxford OX9 8NE

P. M. M. PRITCHARD, M.B., M.R.c.G.P., General Practitioner dialogue to go on between those providing the services and those for whom the services are being provided, and a crucial issue is the "representativeness" of their membership. If the membership of C.H.C.s is felt to exclude significant interest groups their aim of giving a total community view on all services will not be fulfilled.

In establishing the C.P.G. we were confronted with a similar problem. If we were to get representative views on the primary health care services how were we to constitute the C.P.G. ? Much has been published on investigations undertaken to get patients' views on specific issues in primary health care, ${ }^{12}$ but there is little evidence of successful attempts to secure continuing comment and discussion between the providers of primary health care and their public. If our patients were to take seriously our invitation to comment on our services we had to ensure that the C.P.G. was the sort of body through which they were willing to make their views known. This and other issues have continued to concern us during the two and a half years of the C.P.G.'s existence. This paper describes the C.P.G. and the ways in which we have tackled some of these issues.

\section{Background}

The practice serves a population of 6800 , half of whom live in Berinsfield, where the health centre is situated. Berinsfield is a "new village,"3 which was established in 1958 . The other half of the population is in small villages within a radius of five miles of the health centre.

On moving to the health centre in January 1970 the pattern of practice started to change, with emphasis on team work involving treatment room sisters, health visitors, district nurses, and social workers. More patients were able to visit the centre, with the help of voluntary car services, and fewer home visits were undertaken. Laboratory services were used more, and much effort was expended on preventive work and screening. Participative management was encouraged by regular staff meetings. In 1972 the partners felt the need to include patients in this participation, and a group was set up which first met on 30 November 1972. 